\title{
ATYPICAL EEG PATTERN IN CHILDREN WITH ABSENCE SEIZURES
}

\author{
DÉLRIO F. SILVA*, MÁRCIA MARQUES LIMA**, RENATO ANGHINAH**, \\ EDMAR ZANOTELI***, JOSÉ GERALDO CAMARGO LIMA****
}

SUMMARY - We studied four children with diagnosis of absence seizures (generalized primary epilepsy), and with a generalized delta activity on the EEG during clinical attacks provoked by hyperventilation. The lack of ictal generalized spike-and-wave discharges with a frequency of $3 \mathrm{~Hz}$ in our patients, makes this an atypical pattern. All children had complete control of their seizures and disappearance of the EEG changes with valproate. We concluded that generalized delta activity observed on EEG during the hyperventilation in children should not always be considered as a normal finding for age, since it could be an ictal event of an absence seizure.

KEY WORDS: epilepsy, absence seizures, EEG, hyperventilation, delta activity.

\section{Padrão atípico no EEG de crianças com crises de ausência}

RESUMO - Estudamos quatro crianças com o diagnóstico de crises de ausência (epilepsia generalizada primária) e com atividade delta generalizada no EEG, durante crises provocadas pela hiperpnéia. A ausência de descargas generalizadas por complexos ponta-onda a $3 \mathrm{~Hz}$, durante as crises de nossos pacientes, é achado incomum. Todas as crianças tiveram completo controle de suas crises com o valproato, assim como o desaparecimento das alterações no EEG. Concluimos que a atividade delta generalizada observada no EEG de crianças durante a hiperpnéia nem sempre deve ser vista como achado normal, podendo ser um evento crítico da crise generalizada ausência.

PALAVRAS-CHAVE: epilepsia, crises de ausência, EEG, hiperventilação, atividade delta.

Childhood absence seizures is a type of generalized epilepsy, and includes characteristic clinical and EEG manifestations. It is characterized by onset of seizures between the age of 3 and 12 years and a peak at 6-7 years, absence seizures and an EEG finding of generalized spike-and-wave complexes with a typical frequency of $3 \mathrm{~Hz}$. It is well known that during hyperventilation in children, delta activity is frequently seen, and is considered reflexion of a normal development finding ${ }^{25}$. Lee and Kirby (1988) ${ }^{7}$ first reported generalized high amplitude rhythmic delta activity during hyperventilation accompanied by clinical manifestation of staring spells with unresponsiveness.

Our aim in this paper is to describe four children, 6-8 year old, who presented generalized delta activity on EEG during hyperventilation and that were accompanied by clinical seizures.

\section{REPORT OF CASES}

- Case 1: CCOS, a 7-year-old girl had onset of absence seizures four months earlier. Pregnancy and delivery were normal, as was the child's early development. Physical and neurological examinations were normal, as well as computed tomography (CT) scan. Their seizures lasts no longer than a few seconds, occurred up to 4 per day, with no postictal changes. During the absences seizures, there was a loss of awareness and responsiveness

* Head of the EEG Sector, Escola Paulista de Medicina (EPM); ** Junior Doctor of the EEG Sector;***Resident in Neurology; **** Full Professor and Head of the Discipline of Neurology, EPM. Aceite: 2-janeiro-1995.

Dr. Délrio Façanha da Silva - Setor de Eletrencefalografia, Disciplina de Neurologia Clínica, Escola Paulista de Medicina - Rua Botucatu 740 - 04023-900 São Paulo SP - Brasil. 


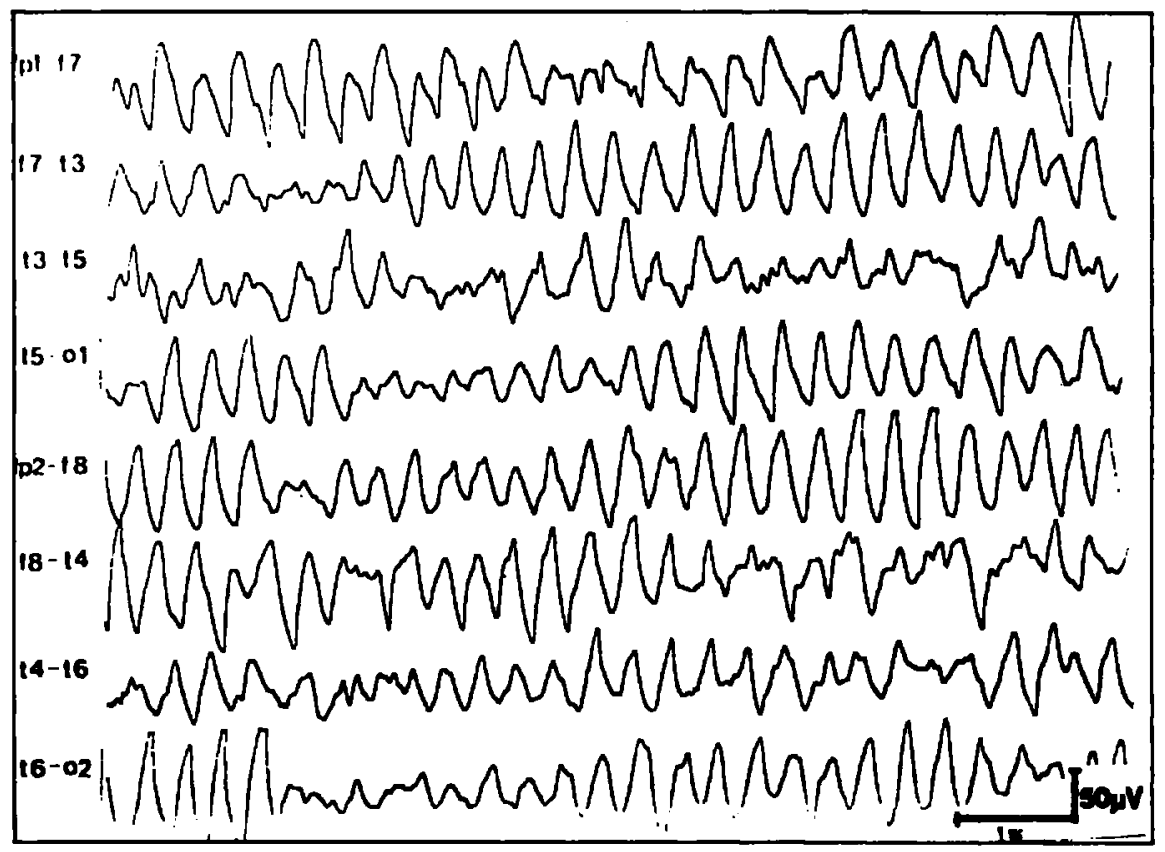

Fig 1. Case 1. Generalized, high amplitude delta activity, during an absence seizure provoked by the hiperventilation.

with interruption of ongoing activities. A conventional EEG (CEEG) recorded for 30 min showed normal background activity (BA); during hyperventilation, five clinical seizures (staring spells with unresponsiveness) were observed with simultaneously generalized high amplitude rhythmic delta activity (Fig 1). With sodium valproate monotherapy, she became completely seizure free. After six months, her 2nd CEEG failed to induce changes during hyperventilation.

Case 2: MSS, a 7-year-old girl suffering from spells since 6 years of age. Pregnancy, birth and psychomotor development were normal. She had a febrile convulsion at the age of 3 years. The absences seizures were characterized by frequent staring spells, lasting some seconds during which she was out and became unresponsive. A CEEG with the child awake and during sleep, showed: (1) normal BA; (2) during hyperventilation three episodes of generalized high amplitude delta activity with clinical staring spells and unresponsiveness; (3) normal EEG during sleep. She was referred to Escola Paulista de Medicina with primidone monotherapy, and became seizure free after sodium valproate monotherapy has been introduced. She was lost to follow-up during 10 months. When a second CEEG was performed, she was completely free of any spells and still with sodium valproate monotherapy. Her CEEG was normal and hyperventilation failed to induce generalized delta activity or clinical absence seizures as previously noted.

Case 3: PSCS, a 8-year-old girl was referred for investigation of abdominal pains. The antenatal and birth histories had been unremarkable. Neurological examination and CT scan were normal. A CEEG showed, during hyperventilation, generalized delta activity accompanied by absence seizures without any warning before clinical manifestation, which were never seen before by her mother. A normal CEEG was observed during sleep. Sodium valproate monotherapy was started. On follow-up at 4 weeks, she was seizure free, but the abdominal pain persisted. A second CEEG recorded after 6 months with the child awake and during sleep was normal without any change during hyperventilation.

Case 4: HTM, a 6-year-old boy had nocturnal nightmares since one year. Pregnancy and delivery were normal as was the child's early development. During hyperventilation in a CEEG, the child presented stereotyped behavioural changes, with interruption of overbreathing, staring and unresponsiveness with automatisms. This 
episode lasted more or less $10 \mathrm{sec}$ and there were no postictal changes. During this absence attack, the EEG showed a generalized delta activity without any spikes. A 2nd. CEEG recorded during sleep was normal. On follow-up at 8 months he was completely free of any seizures with sodium valproate monotherapy and a third CEEG was normal also.

\section{COMMENTS}

It is well known that absence attacks occur spontaneously, but are particularly provoked by hyperventilation. It is the easiest way to provoke an absence seizure and "with a few exceptions, a diagnosis of petit mal should be seriously questioned in the untreated patient who does not have an attack on hyperventilation" ${ }^{\prime 4}$. Three of our patients (Cases 1,3 and 4) were free of treatment and Case 2 was treated without specific anti-epileptic drugs for absence seizures. The most characteristic EEG and behavioural changes occurred during hyperventilation in all cases.

The absence seizures during the hyperventilation were associated with a generalized high amplitude delta activity, rhythmic or, at times, semirhythmic at $2-3 \mathrm{~Hz}$, without any spike or spikeand-wave complexes in all our patients. The EEG BA was normal in all cases and all the clinical features were consistent with the diagnosis of absence seizures: young age, normal children, a chief complaint of staring spells and loss of consciousness, clinical absence seizures during EEG; all patients had complete control of their seizures and disappearance of the EEG changes after sodium valproate monotherapy.

Delta activity is commonly observed in children during hyperventilation and is a phenomenon age-related and should be considered normal ${ }^{2,5}$. This response during hyperventilation in our four patients would be considered normal if the clinical seizures had not been observed during their EEG. Thus, generalized thythmic delta activity can be considered an abnormal finding during hyperventilation in children, when associated with absence seizures, but one be sure that this pattern should not be viewed as epileptic discharges in all cases indiscriminately.

Lee and Kirby ${ }^{7}$ first reported absence seizures with generalized rhythmic delta activity during hyperventilation on the EEG of seven children. Reiher and Lafleur ${ }^{9}$ and Lafleur and Reiher ${ }^{6}$ named it "pseudo-absence" and they considered this phenomenon as a nonepileptic entity, but did not provide reasons and there was no mention about pharmacological interventions in their studies. Our patients were under specific treatment and during the follow-up all of them had complete remission of the EEG changes.

The diagnosis of epileptic seizures is usually made on basis of clinical observation of the attack, EEG findings and favorable response to specific treatment. The differential diagnosis of our patients was made with complex partial seizures, but there was no focal ictal discharge, sodium valproate was effective; sleep EEG recorded in 3 of 4 patients, were normal (Cases 2,3,4), and CT scan realized in one patient (Case 1) was normal too.

Ictal discharges in absence seizures are usually characterized by regular, bilateral, synchronous and symmetrical discharges of rhythmic spike-and-wave complexes at $3 \mathrm{~Hz}$. On the point of vue of clinical aspects, the "petit mal" behavioural absence has been shown to correlate best with the spike discharge rather than the slow wave component ${ }^{3}$. So, why our patients showed absence seizures with atypical EEG without spikes-and-waves complexes? Panet-Raymond and Gotman's studying the BA in epileptic patients state that the region of the brain responsible for epileptic discharges is always abnormal one, and may also generate the development of pathological slow waves in the EEG. Slow waves in the absence of any spike or sharp wave may indicate a distorted reflection of the cerebral dysfunction rather than being the indication of some structural (nonepileptogenic) damage'.

We conclude that generalized delta activity during hyperventilation should not be overlooked in some children and may not always be considered normal, since this finding may be associated 
with absence seizures. A long-term follow-up study and investigation of these children with techniques for intensive monitoring epileptic seizures may add new information about this entity.

\section{REFERENCES}

1. Ajmone-Marsan C. Electroencephalographic studies in seizure disorders: additional considerations. J Clin Neurophysiol 1984, 1:143-157.

2. Eeg-Olofsson $O$. The development of the electroencephalogram in normal children and adolescents from the age of I through 21 years. Acta Paediatr Scand 1971, Suppl 208:1-46.

3. Geier S. Prolonged psychic epileptic seizures: a study of the absence status. Epilepsia 1978, 19:431-444.

4. Holowach J, Thurston DL, O'Leary JL. Petit mal epilepsy. Pediatrics 1962, 30:893-901.

5. Kellaway P. Parameters of the normal EEG: an ordely approach to visual analysis in adults and children. In Klass DW, Daly DD (eds). Current practice of clinical electroencephalography. New York: Raven Press, 1990, p 139-200.

6. Lafleur J, Reiher J. Pseudo-absences. Electroenceph Clin Neurophysiol 1977, 43:279-280.

7. Lee SI, Kirby D. Absence seizures with generalized rhythmic delta activity. Epilepsia 1988, 29:262-267.

8. Panet-Raymond D, Gotman J. Asymmetry in delta activity in patients with focal epilepsy. Electroenceph Clin Neurophysiol 1990, 75:474-481.

9. Reiher J, Lafleur J. Hyperventilation induced cyclic absences (Abstr). Electroenceph Clin Neurophysiol 1977, 42:717. 